\title{
The Use of Body Language in Jordanian Cartoons: A Semiotic analysis
}

Duaa Hajjaj*

Department of English, Faculty of Arts, Tafila Technical University, Jordan

Corresponding Author: Duaa Hajjaj, E-mail: duaa.7a@gmail.com

\section{ARTICLE INFO}

\section{Article history}

Received: January 06, 2018

Accepted: March 18, 2018

Published: June 30, 2018

Volume: 9 Issue: 3

Advance access: May 2018

Conflicts of interest: None

Funding: None

\section{Keywords:}

Semiotics,

Visuals,

Body Language,

Cartoons,

Caricatures,

Meaning,

Connotation,

Media.

\begin{abstract}
This paper presents a semiotic analysis of visuals used in 10 Jordanian cartoons. The cartoons, which were drawn by a number of cartoonists, were collected from online and print media sources. The visuals were examined using the Barthes' (1967) model of signs, which provides a model for analyzing the connotative meanings communicated by the visuals. The results showed the connotative meaning revealed through the use of body language.
\end{abstract}

\section{INTRODUCTION}

In the creation of the visuals such as caricatures of a cartoon, artists often make use of facial expressions, a powerful tool that depicts and evokes emotion. Details such as pallor, smiles, and frowns can communicate emotive experiences and psychological states-of-mind. Expression is depicted through the manipulation of a character's features (e.g. noses, mouths, and eyebrows) and is powerfully effective in revealing the state of the person represented such as emotion, disposition, or personality type. For example, a woman with a wide, open mouth would be interpreted as surprised. A man with lowered eyebrows would be interpreted as angry.

Visuals such as clothing, gestures, facial expressions, and posture are an essential part of nonverbal communication. These visuals are considered to be body language, which can provide additional meaning to nonverbal communication. Danesi (2004) states that:

Body language is the general term used to indicate communication by means of gestures, postures, and other witting and unwitting body signals and signs. It also includes grooming habits, hair and clothing styles, and such practices as tattooing and body piercing. Body language communicates unspoken information about people's identity, relationships, and thoughts, as well as moods, motivation, and attitudes. (p. 53)

Across cultures, body language is a culturally relevant communication. Danesi (2004) states, "Winks, hand gestures, facial expressions, postures, and other bodily actions all communicate something culturally relevant in particular social situations" (p. 46). For example, the head movements for "yes" and "no" differ from one culture to another (Danesi, 2004). In the Balkans, he points out that shaking the head from side to side means "yes," while nodding the head up and down means "no," yet in most other European countries these gestures have exactly the opposite meanings. Additionally, other body language, such as hand gestures, might be different or similar across cultures. Bringing the hands together in the front and bowing may have several cultural meanings: "thank you" in some cultures but "hello" or "goodbye" in others (Matsumoto and Hwang, 2013).

\section{Research Problem}

Recent studies on cartooning genres have shown an interest in analyzing cartoon from various perspectives. However 
there is much attention paid to analyzing cartoons from various perspectives, little attention is paid to the connotative meaning of body language used in them.

\section{Objective of the Study}

The present study aims to analyze the body language used in Jordanian cartoons. It particularly aims to analyze the connotative meaning communicated through it.

\section{THEORETICAL BACKGROUND}

Semiotics, the general science of signs, is a powerful method that can be used to uncover what the body language in a cartoon communicates. Chandler (2007) explains that "semiotics involves the study not only of what we refer to as 'signs' in everyday speech, but [also] of anything which 'stands for' something else" (p. 2). He specifies that "in a semiotic sense, signs take the form of words, images, sounds, gestures and objects" (p. 2).

In his theory of semiotics, Saussure's (1959) presents signs as concepts rather than language elements (words, phrases, etc.). For example, the term 'arbor' is a sign meaning 'tree' in Greek. This term, in his view, must be built psychologically as an idea or concept in the mind before it can be considered as a word in itself. Thus, signs are captured in terms of psychological and cognitive concepts. Linguistic signs (e.g. words) are, for Saussure, concepts and physical and sensory sound images that form together a psychological entity.

Based on Saussure's work, Barthes (1967) explains that every sign has two types of meanings: connotation and denotation. He explains that denotation refers to what or who is being depicted. It is a purely literal and universal meaning (Chandler, 2007: 138). In contrast, Connotation represents ideas or values expressed and the way they are represented (Kress and Leeuwen, 2001). These ideas or values can be represented through cultures-certain connotations would be widely recognized within a culture.

Within the semiotic system, body language is therefore a system of signification that communicates meaning. In regards to body language such as gestures, Danesi (2004) points out that "[m]any semioticians and linguists consider gesture to be a more fundamental form of communication than vocal language" (p. 57). Semiotically, gestures extend the use of body language, and the index finger commonly communicates pointing (Danesi, 2004).

As semiotic analyses are applied to analyze visuals (Berger, 2014) such as cartoons, the current study applied Barthes (1967) semiotic model to analyze the connotative meaning of body language used in Jordanian cartoons.

\section{LITERATURE REVIEW}

Researchers have used semiotic analysis on cartoons to interpret how they communicate various meanings. For example, Akande (2002) considered the use of visual (representations of people) and verbal (linguistic) elements in cartoons, highlighting that cartoons are viewed as a valuable tool for public discussion of polemic issues rather than trivial entertainment. He AkandeHeHeexplained how meaning in these cartoons is conveyed in relation to the sociopolitical context.

On the other hand, Sani, Abdullah, Ali and Abdullah (2012) applied a semiotic theory to develop a classification for the lexical distribution in cartoons and to draw attention to the function of these classes, including the lexical category 'coinage' functions to express humor.

\section{METHODOLOGY}

The sample consists of 10 cartoons taken from various Jordanian media sources and drawn by different cartoonists. The cartoons were published in alghad's printed and electronic daily newspapers, almadenahnews (an electronic newspaper), and the Jordanian websites hkjtoday.com, comicarabia, and islahjo.com.

Homogenous sampling, a form of purposive sampling, is used for the representative sample of the population. It requires the researcher to select a sample based on shared characteristics (Cohen and Crabtree, 2006). As the present study's purpose was to analyze the body language of clothing, gestures, facial expressions, and posture, cartoons containing these types of body language were purposively selected.

\section{DISCUSSION AND ANALYSIS}

This section presents the semiotic analyses of the 10 Jordanian cartoons. It looks at how the cartoons use clothing, gestures, facial expressions, and posture to communicate meanings.

\section{Clothing}

Clothing conveys meaning that shows power relationships among people (Owyong, 2009), and this was found in two of the 10 cartoons. Some of these cartoons showed the more powerful speaker wears a tie and the less powerful character wears none. In some cartoons, all characters wore suits, but the suits on the more powerful characters looked neater and more expensive. The less powerful characters wore items that undermined their power, including a bib and a dance belt.

For example, Figure 1 shows a cartoon in which the speaker is clothed in a formal suit with a tie, typical clothing worn at formal occasions or at work by those who hold high positions. These clothes indicate that the speaker is a prominent figure with the associated power, and particularly the power over the other character. In contrast, the other character's clothing connotes little-if any-power at all. Interestingly, this cartoon shows a baby's bib where the expected tie would be connoting this character's lack of power: the bib reflects infantilism, childish behavior, a baby-like need to be guided or controlled by others. These features clearly communicate the unequal distribution of power between the characters.

Moreover, clothing also reflects characters' personality (Moody, Wendy, Sinha, \& Pammi, 2010). For example, clothing conveys caricatures' irresponsibility. In Figure 2, 


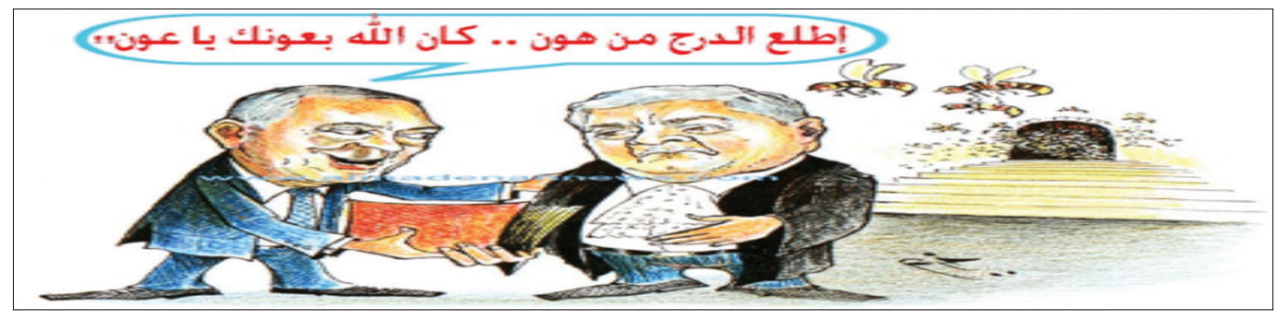

Figure 1. Kharim, H. (2014, August 10) [Cartoon]. Retrieved from http://www.almadenahnews.com/mobile/article/11181

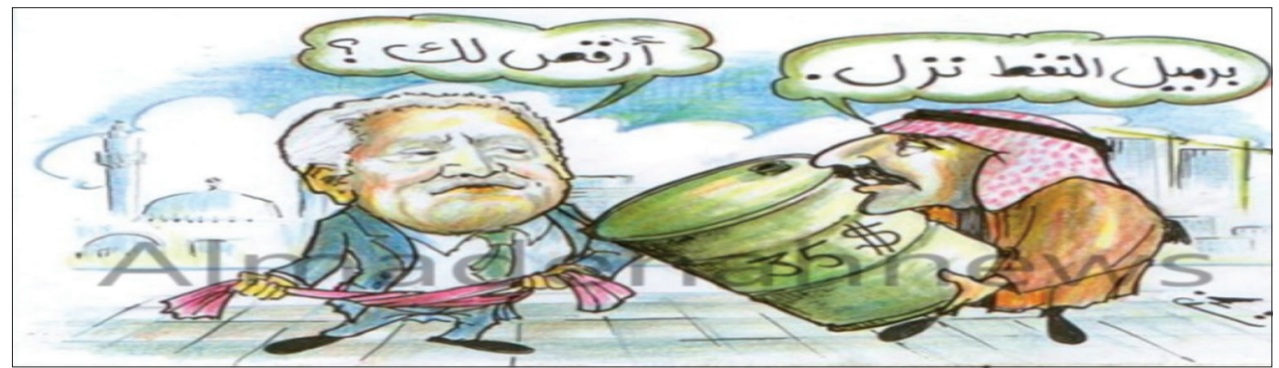

Figure 2. Kharim, H. (2016, June 12) [Cartoon]. Retrieved from http://www.almadenahnews.com/mobile/article/436718

the dance belt is paired with a well-fitted suit, which makes the use of the dance belt more striking. The dance belt serves to undermine the authority connoted by the suit, suggesting that the speaker does not effectively have the power he is seen to have, or perhaps thinks he has. Therefore, he does not have the authority to make decisions, give orders, or to bear any kind of responsibility.

In the cartoons analysed for this study, irresponsibility was also shown by using an oversized suit. For example, in Figure 3, although the character on the right wears a suit, shirt, and tie, the jacket of the suit is too large. This oversized suit is associated with characters that take no responsibility for what they wear, connoting that they are not responsible for any of their actions.

Clothes serve as another type of nonverbal communication (Tijana, Tomaž, \& Čuden, 2014), providing non-verbal clues regarding the wearer's situations. Although previous research has not looked at how clothing details are used to communicate characters' situations, this study found that the use of empty pockets and patched clothes helps the reader infer information about the characters wearing them. Figure 3 provides an example of how these clothing details communicate misery. The character on the left (Figure 3) wears a patched jacket and carries a bag that is patched and has a hole in it. On the other hand, Figure 4 shows a character's pockets turned outward to reveal that they are empty, which depicts his financial situation, showing he is penniless, connoting the misery that results from the high cost of living.

\section{Gestures}

In addition to clothing, gestures, such as nodding the head to communicate agreement, are a type of body language used to communicate meaning non-verbally (Houman and Flammia, 2010). In these cartoons, hand gestures were found to be a salient feature and were used in various ways, such as exchanging handshakes, to show the relationships among characters. For example, Figure 5 shows the characters grasp each other's hands. While doing so, the speaker is placing a hand on the addressee's shoulder. This style of handshake communicates that these characters trust each other and have a harmonious relationship.

Hands were also used in these cartoons to reflect emotions. For example, in Figure 6, the addressee is drawn with her hand on her face, illustrating the character's shame at being attacked by the other character.

In these cartoons, the Pointing fingers is another hand gesture used in these cartoons, connoting negative and aggressive behaviours toward the characters to which the fingers are directed. In Figure 6, the speaker's pointed index finger, directed to an accused, the addressee, connotes aggression. The speaker's hand gesture (palm facing up), on the other hand, is a gesture pointing to a direction where one is supposed to go (see Figure 8).

\section{Facial Expressions}

Facial expressions are another important communicative means of body language and they are typically an associations for emotions (Elliott and Jacobs, 2013). The face is considered as the most effective channel that expresses specific emotion (Ekman, 1965). In the cartoons analysed, facial expressions were most often used to show the characters' emotional state or attitude. For example, the speaker's eyes in Figure 7 are closed as he plays the jigsaw puzzle, representing a long and tedious task, and appears to not be able to finish it. Therefore, the closed eyes connote tiredness or exhaustion.

Smiles can convey happiness, pleasure, or even irritation (Sandra, 2003). In case of Figure 2, the study found that the facial expressions such as the smiling on the old man's face symbolizes a happy or at least pleased character.

The tongue and mouth were used in these cartoons to signify the attitudes of characters. For example, in Figure 8, the speaker on the left spreads his tongue and has a mouth that is drawn wide open, which communicates the action of shouting, or at least speaking loudly. 


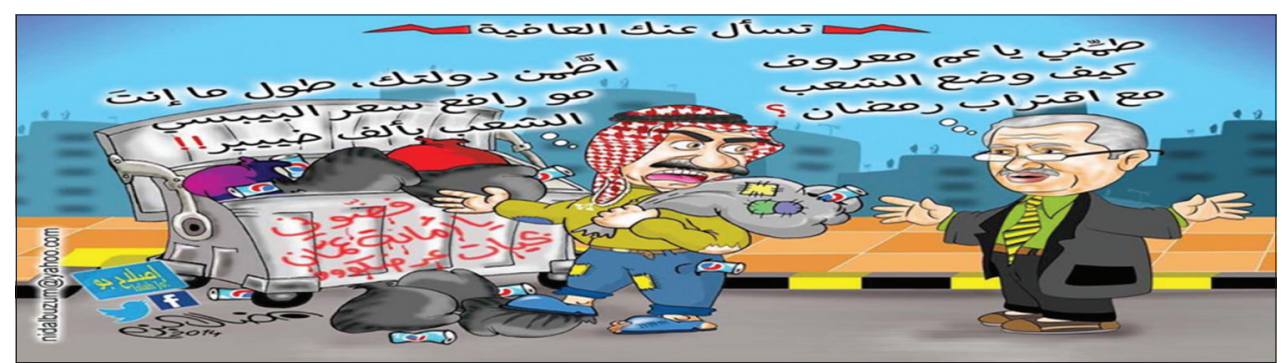

Figure 3. Al Jafari, N. (2014, December 8) [Cartoon]. Retrieved from http://www.alghad.com/articles/841061

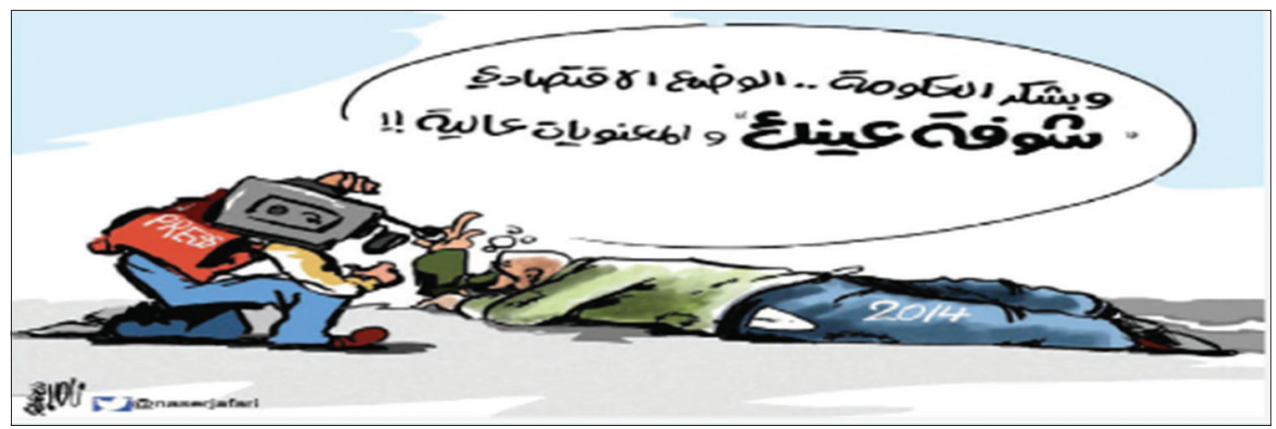

Figure 4. Al Jafari, N. (2014, December 8) [Cartoon]. Retrieved from http://www.alghad.com/articles/841061

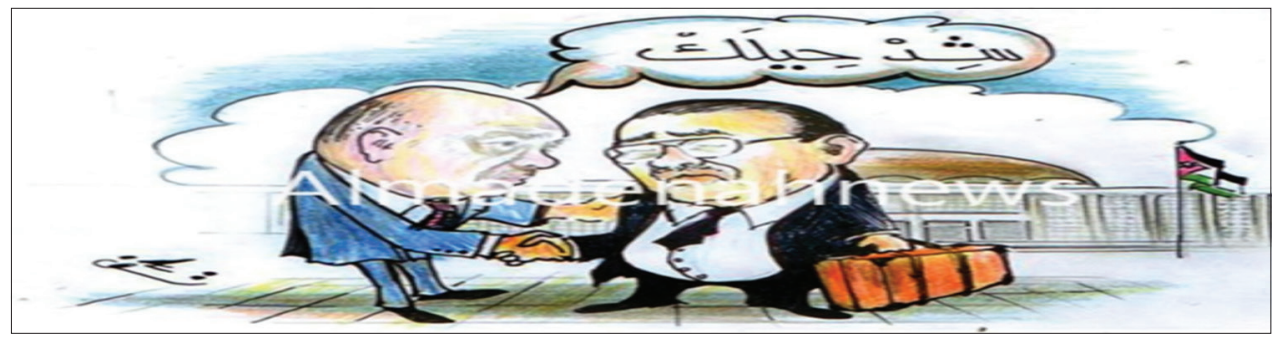

Figure 5. Kharim, H. (2015, October 29) [Cartoon]. Retrieved from http://www.almadenahnews.com/article/423769

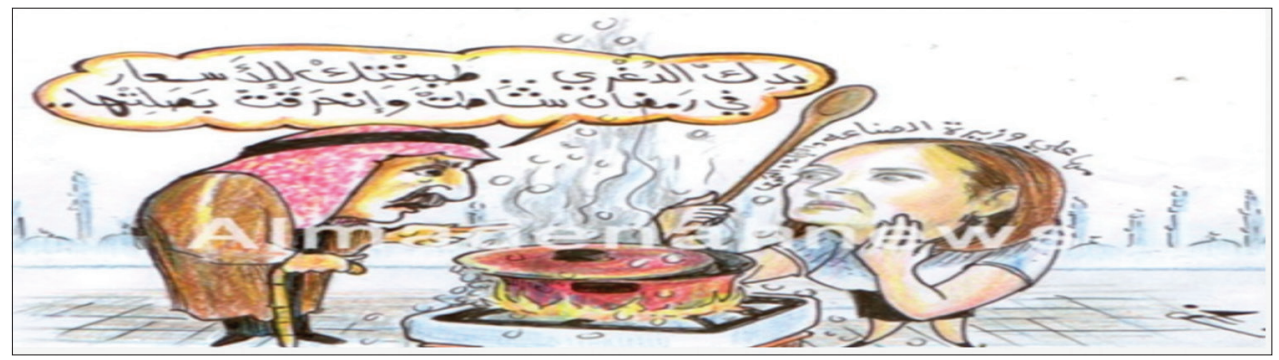

Figure 6. Kharim, H. (2015, June 7) [Cartoon]. 'Retrieved from http://www.almadenahnews.com/article/385789

\section{Posture}

Another meaningful use of body language in Jordanian cartoons is posture, such as standing, hunching over, or lying. Harrigan (2005) identifies posture as a coding system employing the descriptors including trunk orientation (e.g., turned) and legs positions (e.g., crossed). Posture in this study has a range of meanings and even the same posture can connote extremely different-even opposite-meanings. For example, in Figure 9, the petrol pump is drawn with a hunched back as it addresses another character; the petrol pump also leaves a very narrow space between itself and the other character. This invasion of space communicates the sense of aggression, giving meaning to the petrol pump's actions and language.
In Figure 10, the character on the left is also drawn with a hunched back, supporting himself with a cane and looking up slightly at the other character. Visually, this posture suggests humble behaviour, a very different meaning from that communicated by the hunched back in Figure 9.

Another use of posture is to show characters' confidence and power, and this use can be seen in two of the previous figures: Figure 3 and Figure 4. In figure 3, the character on the right is a confident character: he is standing with legs together and arms spread. The character's upright posture communicates a sense of confidence. A body lying down is used to connote powerlessness in Figure 4, in which the character is on the ground on his stomach and in a sleeping position, even though he is not asleep. 


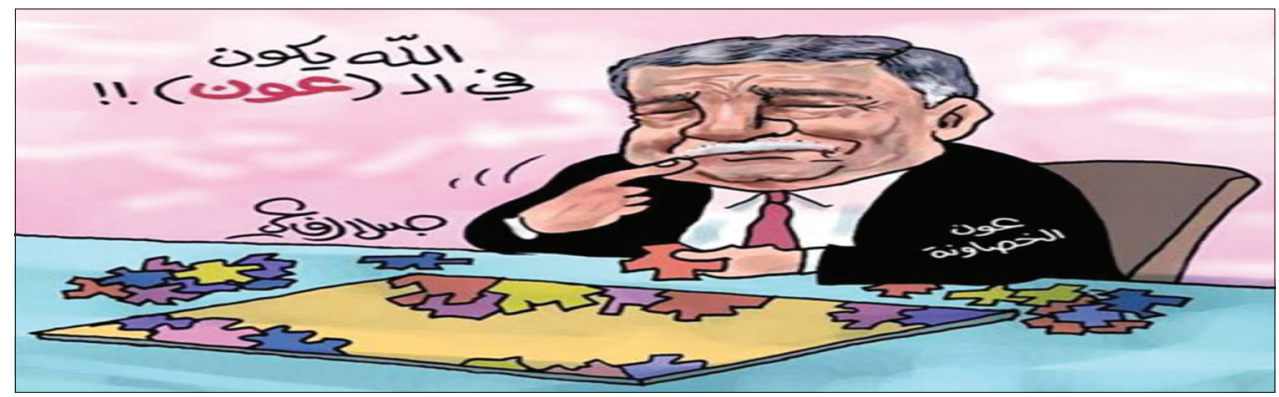

Figure 7. Al Rifai, J. (2012, January 30) [Cartoon]. Retrieved from http://www.hkjtoday.com/article.php?id=18929

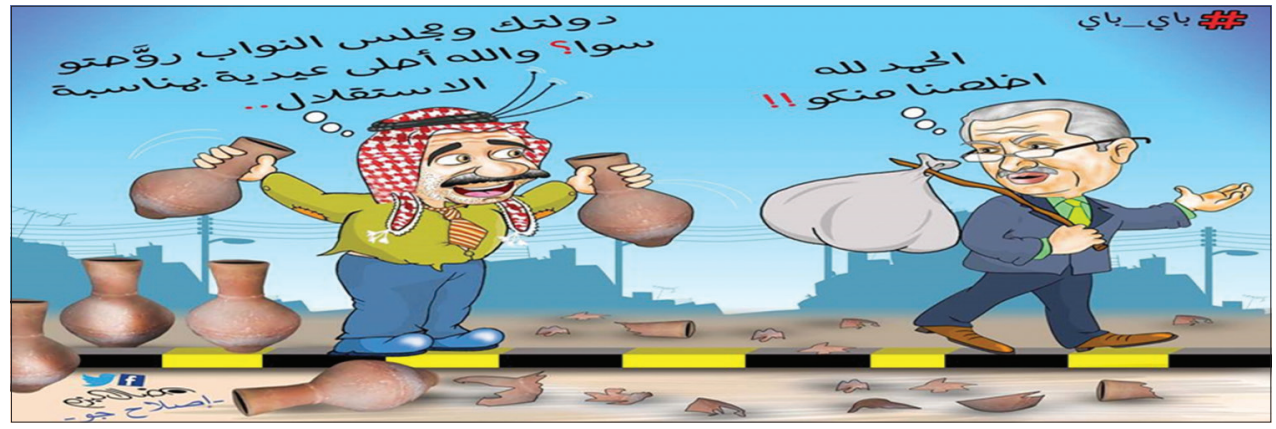

Figure 8. Albuzum, N. (2016, May 29) [Cartoon]. Retrieved from http://islahjo.com/35161

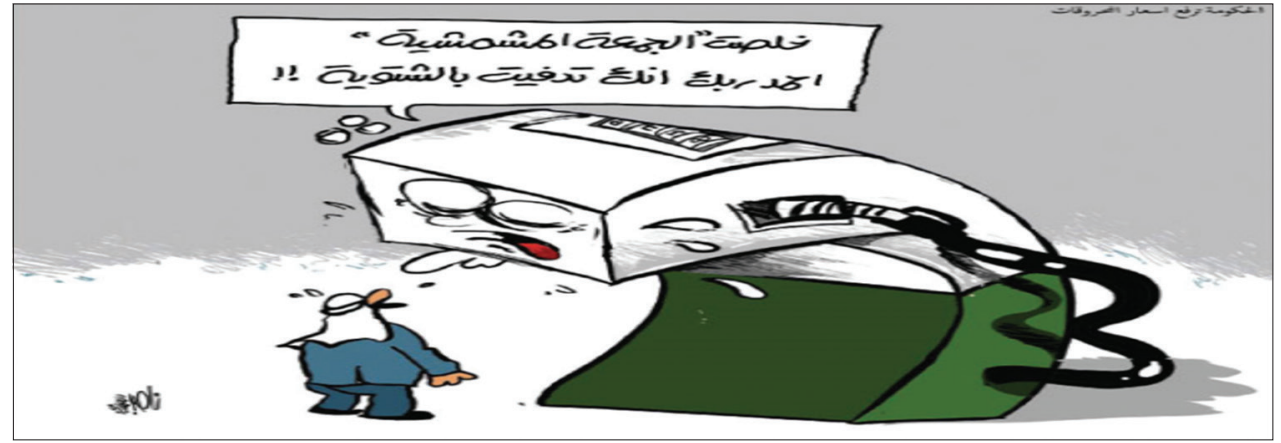

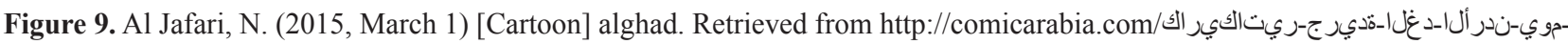
أل25/

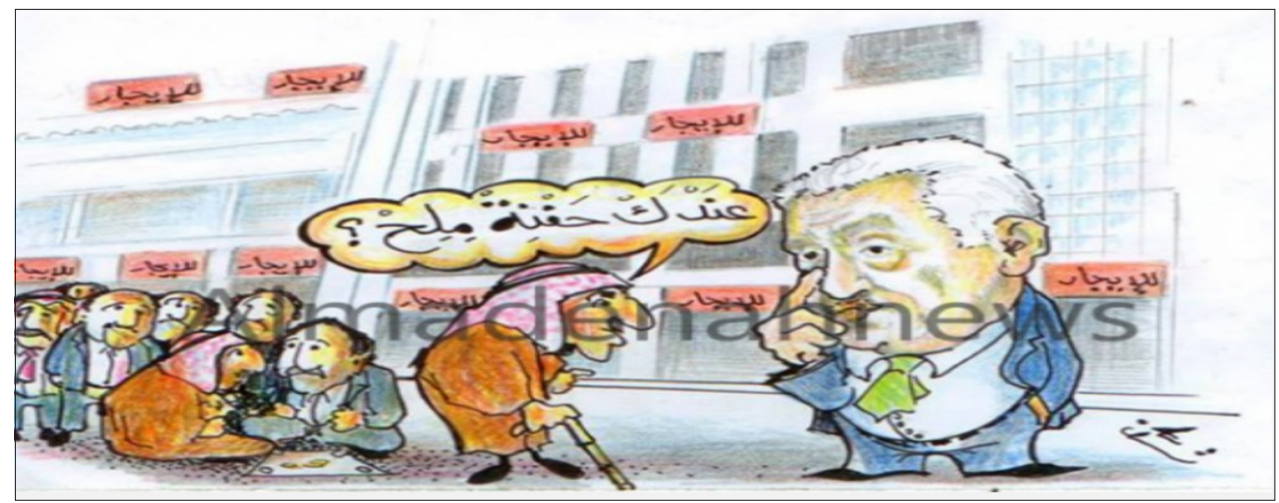

Figure 10. Kharim, H. (2015, September 20) [Cartoon]. Retrieved from http://www.almadenahnews.com/article/413057

\section{CONCLUSION}

The aim of the present study was to analyse the body language used in cartoons. It analysed the connotative meaning communicated through it. This semiotic analysis of the visuals in the 10 Jordanian cartoons has shown that visuals used in Jordanian cartoons communicate various connotative meanings. In these cartoons, clothing was used to show the power relationships between characters, the level of responsibility that characters takes on, and other details about the characters, such as levels of misery. Gestures were used to show characters' personality traits or emotions, while facial expressions were used to indicate the characters' emotional 
states or attitudes. Posture communicated characters' actions or behaviours. In particular, the use of posture was distinctive from the other body language features as the same posture was used to show two opposite meanings in two of the cartoons analyzed.

\section{RECOMMENDATIONS}

The present study focused on the connotative meaning of body language used in Jordanian cartoons, looking specifically at clothing, gestures, facial expressions, and posture. Body language is a crucial part of nonverbal communication, and understanding — or not — can be closely tied to how body language is presented and interpreted. Future studies could contribute by looking at how these same types of body language are used to connote other meanings in both similar and different cultures.

\section{REFERENCES}

Akande, O. (2002). A Semiotic Analysis of Political Cartoons: A case study of Nigeria (Unpublished Doctoral Dissertation). University of Oklahoma, Norman, USA.

Barthes, R. (1967). Elements of Semiology. (Translated by Annette L. and Smith C.) New york: Hill and Wang.

Berger, A. (2014). Media Analysis Techniques. ( $2^{\text {nd }}$ ed.). Thousand Oaks, CA: Sage.

Chandler, D. (2007). Semiotics: the basics, ( $2^{\text {nd }}$ ed.). New York: Routledge.

Cohen, D. \& Crabtree, B. (2006). Qualitative research guidelines project. Retrieved from http://www.qualres. org/HomeHomo-3804.html

Danesi, M. (2004). Messages, signs, and meanings: A basic locutionary actbook in semiotics and communication theory. Toronto: Canadian Scholars' Press Inc.

Ekman, P. (1965). Differential Communication of Affect by Head and Body Cues. Journal of Personality and Social Psychology, 2 (5): 726.
Elliott, E. and Jacobs A. (2013). Facial Expressions, Emotions, and Sign Language. Front Psychol, 4: (115).

Harrigan, J. (2005). Proxemics, kinesics, and gaze. In J. A. Harrigan, R. Rosenthal, \& K. Scherer (Eds.), The new handbook of methods in nonverbal behavior research (pp. 137198). New York: Oxford University Press.

Kress, G. and Leeuwen, T. (2001). Multimodal discourse: the modes and media of contemporary communication, London: Arnold.

Houman, A. and Flammia, M. (2010). Intercultural Communication: A New Approach to International Relations and Global Challenges. IEEE Transactions on Professional Communication, 56(1).

Matsumoto, D. and Hwang, H. (2013). Cultural Similarities and Differences in Emblematic Gestures. Nonverbal Behav, 37:1-27.

Moody, Wendy, Sinha, and Pammi (2010). An Exploratory study: Relationships between Trying

on Clothing, Mood, Emotion, Personality, and Clothing Preference. Journal of Fashion Marketing and Management, 14 (1): 161-179.

Owyong. Y (2009). Clothing semiotics and the social construction of power relations. Social Semiotics, 19(2), 191-211.

Sandra C. (2003). The Communication Handbook: A Student Guide to Effective Communication. Lansdowne: Juta and Co. Ltd.

Sani, I. Abdullah, M. Ali, A. and Abdullah, F. (2012b). Linguistic analysis on the construction of satire in Nigerian political cartoons: The example of newspaper cartoons. Journal of Media and Communication Studies, 4(3): 52-59.

Saussure, F. (1959). Course in General Linguistics. Translated by Wade, B. New York: Mc Graw - Hill Book Company.

Tijana, T. Tomaž, T. and Čuden, A. (2014). Clothes and Costumes as Form of Nonverbal

Communication. Pregledni znanstveni članek, 75(4): 321-333. 